\title{
Effect of hormone therapy, tibolone and raloxifene on circulating vascular endothelial growth factor in Greek postmenopausal women
}

\author{
G Christodoulakos, I Lambrinoudaki, C Panoulis, C Papadias, A Sarandakou ${ }^{1}$, T Liakakos, A Alexandrou ${ }^{2}$ \\ and G Creatsas \\ 2nd Department of Obstetrics and Gynecology, University of Athens, Aretaieion Hospital, Athens, Greece, ${ }^{1}$ Hormonal Laboratory, University of Athens, \\ Aretaieion Hospital, Athens, Greece and ${ }^{2} 2$ d Department of Surgery, University of Athens, Laikon Hospital, Athens, Greece \\ (Correspondence should be addressed to I Lambrinoudaki, 18 Kifissias Street, Ambelokipoi, GR-11526, Athens, Greece; \\ Email: ilambrinoudaki@hotmail.com)
}

\begin{abstract}
Objective: To evaluate the effect of continuous combined hormone therapy (HT), tibolone and raloxifene on circulating vascular endothelial growth factor (VEGF) in postmenopausal women. Design: One-year prospective intervention study.

Methods: One hundred and forty-six postmenopausal women with a mean age of $51.8 \pm 4.1$ (S.D.) years received $0.625 \mathrm{mg}$ conjugated equine estrogen (CEE) plus $5 \mathrm{mg}$ medroxyprogesterone acetate (MPA) (CEE/MPA, $n=34), 2.5 \mathrm{mg}$ tibolone $(n=37), 60 \mathrm{mg}$ raloxifene $(n=40)$ or no active treatment (control group, $n=35$ ). Plasma VEGF was estimated at baseline and at 6 and 12 months. Results: In both the CEE/MPA-treated and the tibolone-treated groups plasma VEGF increased significantly at month 6 and remained elevated at month 12 (CEE/MPA baseline: $268.1 \pm 187.8 \mathrm{pg} / \mathrm{ml}$, month 6: $320.0 \pm 175.3 \mathrm{pg} / \mathrm{ml}$, month $12: 321.1 \pm 181.8 \mathrm{pg} / \mathrm{ml}, \quad P=0.01$; tibolone baseline: $240.6 \pm 165.8 \mathrm{pg} / \mathrm{ml}$, month $6: 271.4 \pm 172.7 \mathrm{pg} / \mathrm{ml}$, month $12: 274.8 \pm 183.1 \mathrm{pg} / \mathrm{ml}, P=0.03)$. These changes were significantly different from the respective changes in the control group after adjusting for T-score in bone densitometry (CEE/MPA: $P=0.02$, tibolone: $P=0.04$ ). The effect of HT or tibolone on plasma VEGF was mainly evident in women with low baseline VEGF levels $(<243.2 \mathrm{pg} / \mathrm{ml}$, median for whole sample). On the contrary, VEGF levels in the raloxifene-treated or the control group did not change throughout the study.

Conclusion: Both continuous combined HT and tibolone increased circulating VEGF in postmenopausal women, while raloxifene had no effect. Further research is needed to clarify the clinical relevance of these findings with respect to cardiovascular risk in postmenopausal women.
\end{abstract}

European Journal of Endocrinology 151 187-192

\section{Introduction}

Menopause-related estrogen depletion has been associated with an increased risk for cardiovascular disease (CVD) (1). Observational studies have suggested that hormone therapy (HT) expresses an anti-atherogenic profile via mechanisms which include favorable lipidlipoprotein alterations (2), a decrease in homocysteine serum levels (3) and an increase in nitric oxide:endothelin ratio (4). However, this suggested cardioprotective effect among postmenopausal women has been seriously questioned by the Women's Health Initiative (5) and the Heart and Estrogen/Progestin Replacement studies (6). In the aftermath of these randomized studies, clinical and experimental research has focused on further clarifying the effect of various factors on the vascular wall and endothelium as well as the possible variable effect of different HT regimens and routes of administration in the genesis and evolution of atherosclerosis.

Vascular endothelial growth factor (VEGF) is a multifunctional cytokine which is a potent endogenous regulator of endothelial cell (EC) integrity and function. VEGF enhances microvascular permeability and modulates thrombogenicity, as the extravasation of plasma and plasma proteins may trigger clotting mechanisms. Most importantly, VEGF mediates EC proliferation, differentiation and migration, while inhibiting apoptosis. As such, VEGF is a potent angiogenic factor associated with pathophysiological angiogenesis $(7,8)$.

VEGF expression and angiogenesis may be under the influence of ovarian hormones, as manifest in the periodic growth-regression changes which characterize the function of the ovary and endometrium (9). Most 
normal tissues do not express measurable levels of either VEGF or its receptors VEGF R-1 (flt-1) and VEGF R-2 (kinase insert domain containing receptor (KDR)/flk-1) which are tyrosine kinase-type transmembrane receptors, present especially on ECs $(8,10)$. VEGF expression may be modulated by age and age-associated hypercholesterolemia and endothelial dysfunction (11). Following menopause, the reproductive tract ceases to be a major source of circulating VEGF and serum levels are expected to fall. Indeed VEGF serum levels are higher in premenopausal women compared with postmenopausal women (12).

Normal coronary arteries do not express VEGF (1). However, during atherosclerosis, arterial obstruction and the resultant hypoxia induce VEGF expression, not only by ECs, but also by vascular smooth muscle cells and macrophages $(10,13)$. Although extensive data link VEGF to human atherosclerosis, the role of VEGF in the genesis and progression of CVD is still debated $(1,14)$. As an endogenous local regulator of EC integrity-function, VEGF may project a protective effect and delay or prevent atherosclerosis (15). Furthermore, neoangiogenesis, in the form of functional collateral circulation, during early coronary obstruction may also be beneficial by providing tissue nutrients (16). In contrast, in advanced atheromatosis, neovascularization of the plaque may be detrimental, for it may alter plaque stability and cause its rupture (17).

The purpose of this study was to investigate the effect of HT, tibolone and raloxifene on serum VEGF levels among healthy postmenopausal women.

\section{Materials and methods}

One hundred and sixty postmenopausal women aged 45-62 years were included in the study. Subjects were recruited from the Menopause Clinic of the 2 nd Department of Obstetrics and Gynecology, University of Athens, Aretaieion Hospital. Patients were at least 2 years postmenopausal; women less than 3 years postmenopausal had follicle-stimulating hormone (FSH) and estradiol (E2) estimations to confirm postmenopausal status (FSH $>40 \mathrm{mIU} / \mathrm{ml}$ and $\mathrm{E} 2<30 \mathrm{pg} / \mathrm{ml}$ ). Women who were past users of HT, tibolone or raloxifene were not included in the study unless they had been off therapy for at least 6 months.

Before commencing therapy, patients had a gynecological and biochemical evaluation which included: bimanual examination, papanicolaou (PAP) smear and transvaginal sonography, breast examination and mammography, thyroid-liver-renal function as well as blood coagulation tests and bone densitometry by dual energy X-ray absorptiometry (DEXA). Criteria for inclusion in the study were the absence of climacteric complaints, the presence of an intact uterus with an endometrial thickness $<5 \mathrm{~mm}$ and the absence of a history of gynecological malignancy, ischemic heart disease, thromboembolism, diabetes mellitus, non-treated thyroid dysfunction and the intake of lipid-lowering or anti-hypertensive medication.

The decision to treat was based on the presence of osteopenia or osteoporosis (T-score in bone densitometry $<-1$ ). One hundred and twenty-two women with T-score $<-1$ were randomly assigned either to $0.625 \mathrm{mg}$ conjugated equine estrogens (CEE) plus $5 \mathrm{mg}$ medroxyprogesterone acetate (MPA) (CEE/MPA; Premelle 5; Wyeth-Ayerst Laboratories, Philadelphia, PA, USA; $n=40$ ), $2.5 \mathrm{mg}$ tibolone (Livial; Organon, Oss, The Netherlands; $n=41$ ) or $60 \mathrm{mg}$ raloxifene $\mathrm{HCl}$ (Evista; Eli-Lilly, Indianapolis, IN, USA; $n=41$ ). Women with normal bone mineral density received no therapy and served as controls $(n=38)$. All subjects received daily supplemental calcium $(500 \mathrm{mg})$ and vitamin D (200 IU). Informed consent was signed by every participant and Institutional Review Board approval was obtained by the Ethics Committee of Aretaieion Hospital.

The study period was 12 months. Blood pressure, weight and height were recorded in the morning in light clothing and body mass index (BMI) was computed before commencing therapy and at the end of 6 and 12 months. Accordingly, fasting blood samples were drawn at $0900 \mathrm{~h}$ at baseline and at 6 and 12 months. Samples collected in EDTA-containing polystyrene tubes were immediately centrifuged and plasma was stored at $-80^{\circ} \mathrm{C}$ until assayed.

From the original 160 women, 146 completed the 12 -month protocol. Nine women were lost to followup, four subjects discontinued treatment because of unscheduled vaginal bleeding (all in the CEE/MPA-treated group) and one subject discontinued treatment because of weight gain (tibolone-treated group).

VEGF concentrations were measured by a commercial kit (human VEGF; Quantikine; R\&D Systems, Minneapolis, MI, USA. The within-assay and between-assay coefficients of variation were $4.5 \%$ and $7.0 \%$ respectively. The sensitivity of the method was $5 \mathrm{pg} / \mathrm{ml}$. Total cholesterol (TC), high density lipoprotein-cholesterol (HDL-C) and triglycerides (TG) were assessed enzymatically by an autoanalyzer (COBAS-MIRA; Roche Diagnostics Ltd, Lewes, E Sussex, UK). Low density lipoprotein (LDL)-cholesterol (LDL-C) was estimated as described by Friedewald (LDL-C $=$ TC - TG/ $5-$ HDLC) (18). Apolipoprotein A1 (ApoA1) and apolipoprotein $\mathrm{B}$ (ApoB) were determined by an immunoturbimetric assay (ABX Diagnostics, Montpellier, France).

Statistical analysis was performed by SPSS Version 8.0 (Statistical Package for the Social Sciences, Chicago, IL, USA). Baseline characteristics between women who completed the study and women who dropped out were compared by Student's t-test for unpaired observations. Only women who completed the protocol were entered into further analysis $(n=146)$. Baseline demographic characteristics and baseline lipid, apolipoprotein and VEGF levels were compared between therapy groups by ANOVA. Changes 
in VEGF concentrations throughout the study period across the same group were evaluated by analysis of variances for repeated measures. Changes in VEGF levels between groups were evaluated by analysis of covariances with T-score as assessed in bone densitometry as a covariate. Statistical significance was set at the 0.05 level.

\section{Results}

Baseline demographic characteristics, lipid, lipoprotein and VEGF levels were not different between women who completed the study $(n=146)$ and women who dropped out $(n=14)$. Furthermore, no difference was detected with respect to the above-mentioned parameters between treatment and control groups in women who completed the 1-year study (Table 1).

Pearson correlation coefficients between baseline lipid, apolipoprotein and VEGF plasma levels are presented in Table 2. Baseline VEGF levels exhibited a positive correlation between baseline serum ApoB ( $r=0.31, P<0.05)$. No other correlation was found between VEGF and lipids or ApoA1.
In both the CEE/MPA- and the tibolone-treated groups, plasma VEGF increased significantly at month 6 and remained elevated at month 12 [CEE/MPA

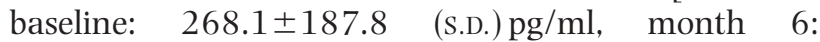
$320.0 \pm 175.3 \mathrm{pg} / \mathrm{ml}$, month $12: 321.1 \pm 181.8 \mathrm{pg} / \mathrm{ml}$, $P=0.01$; tibolone baseline: $240.6 \pm 165.8 \mathrm{pg} / \mathrm{ml}$, month 6: $271.4 \pm 172.7 \mathrm{pg} / \mathrm{ml}$, month 12: $274.8 \pm 183.1 \mathrm{pg} / \mathrm{ml}, P=0.03]$. These changes were significantly different from the respective changes in the control group after adjusting for T-score in bone densitometry (CEE/MPA: $P=0.02$, tibolone: $P=0.04)$. On the contrary, VEGF levels in the raloxifene-treated or the control group did not change throughout the study [raloxifene baseline: $241.2 \pm 177.6 \mathrm{pg} / \mathrm{ml}$, month 6: $256.1 \pm 196.7 \mathrm{pg} / \mathrm{ml}$, month 12: $259.5 \pm 197.2 \mathrm{pg} / \mathrm{ml}, P=0.65$, compared with controls $P=0.83$; control group baseline: $247.0 \pm 150.6 \mathrm{pg} / \mathrm{ml}$, month 6: $249.5 \pm 154.8 \mathrm{pg} / \mathrm{ml}$, month 12: $247.9 \pm 153.5 \mathrm{pg} / \mathrm{ml}, P=0.69]$.

Statistical analysis was repeated in subgroups of women with low VEGF $(<243.2 \mathrm{pg} / \mathrm{ml}$, median for whole sample) and high baseline VEGF $(>243.2$ pg/ml; Fig. 1). The effect of CEE/MPA and tibolone

Table 1 Baseline characteristics of 146 healthy postmenopausal women who completed the study according to treatment assignment.

\begin{tabular}{|c|c|c|c|c|c|}
\hline Variable & Controls $(n=35)$ & CEE/MPA $(n=34)$ & Tibolone $(n=37)$ & Raloxifene $(n=40)$ & $\boldsymbol{P}^{\star}$ \\
\hline \multicolumn{6}{|l|}{ Continuous variables (mean (S.D.)) } \\
\hline Age (years) & $50.4(5.2)$ & $50.9(4.0)$ & $52.1(3.6)$ & $51.3(4.3)$ & 0.32 \\
\hline Years since menopause & $3.5(3.1)$ & $3.9(3.3)$ & $4.1(4.3)$ & $4.0(4.2)$ & 0.29 \\
\hline BMI $\left(\mathrm{kg} / \mathrm{m}^{2}\right)$ & $25.6(3.3)$ & $24.3(2.9)$ & $25.5(2.9)$ & $25.2(2.4)$ & 0.51 \\
\hline Estradiol (pg/ml) & $12.1(8.4)$ & $11.3(7.9)$ & $14.5(7.1)$ & $13.7(8.7)$ & 0.66 \\
\hline $\mathrm{FSH}(\mathrm{mlU} / \mathrm{ml})$ & $72.6(45.1)$ & $69.8(32.5)$ & $62.7(29.9)$ & $77.5(57.5)$ & 0.89 \\
\hline Systolic arterial pressure $(\mathrm{mmHg})$ & $131(22)$ & $128(28)$ & $138(26)$ & $122(31)$ & 0.84 \\
\hline Diastolic arterial pressure $(\mathrm{mmHg})$ & $89(8)$ & $83(9)$ & $81(6)$ & $85(7)$ & 0.64 \\
\hline Serum VEGF (pg/ml) & $247.0(150.6)$ & $268.1(187.8)$ & $240.6(165.8)$ & $241.2(177.6)$ & 0.43 \\
\hline Cholesterol (mg/dl) & $238.2(48.3)$ & $230.0(33.2)$ & $236.8(54.4)$ & $241.2(43.4)$ & 0.70 \\
\hline LDL-C (mg/dl) & $157.7(37.1)$ & $153.9(28.7)$ & $160.3(49.5)$ & $159.5(38.0)$ & 0.81 \\
\hline HDL-C (mg/dl) & $53.1(10.3)$ & $58.9(10.7)$ & $54.3(14.3)$ & $54.9(11.9)$ & 0.49 \\
\hline Triglycerides (mg/dl) & 98.8 (38.2) & $96.1(27.9)$ & $101.5(39.5)$ & $104.7(51.6)$ & 0.25 \\
\hline ApoA1 (mg/dl) & $168.0(25.7)$ & $181.4(28.9)$ & $166.4(26.6)$ & $163.2(31.5)$ & 0.19 \\
\hline ApoB (mg/dl) & $111.7(41.0)$ & $111.6(26.2)$ & $119.2(36.3)$ & $115.1(27.7)$ & 0.87 \\
\hline \multicolumn{6}{|l|}{ Categorical variables (\%) } \\
\hline Current smoking ( $\geq 10$ cigarettes/day) & 40.1 & 34.8 & 42.7 & 36.2 & 0.32 \\
\hline Alcohol (8g/day) & 1.2 & 2.3 & 1.8 & 2.1 & 0.45 \\
\hline Physical exercise (>3h/week) & 28.2 & 36.4 & 31.6 & 29.8 & 0.51 \\
\hline
\end{tabular}

*Comparisons between groups by ANOVA.

Table 2 Pearson correlation coefficients between baseline serum VEGF, lipid and apolipoptotein levels in the 146 postmenopausal women who completed the study.

\begin{tabular}{|c|c|c|c|c|c|c|c|}
\hline & VEGF & Total cholesterol & LDL-C & HDL-C & TG & ApoA1 & AроB \\
\hline VEGF & 1 & 0.16 & 0.14 & -0.041 & 0.26 & 0.015 & $0.31^{*}$ \\
\hline Total cholesterol (mg/dl) & & 1 & $0.94^{\star * *}$ & 0.21 & $0.43^{\star \star}$ & 0.21 & $0.48^{\star \star}$ \\
\hline LDL-C (mg/dl) & & & 1 & -0.02 & $0.33^{\star \star}$ & 0.05 & $0.43^{\star *}$ \\
\hline HDL-C (mg/dl) & & & & 1 & -0.21 & $0.6^{\star \star \star}$ & -0.04 \\
\hline $\mathrm{TG}(\mathrm{mg} / \mathrm{dl})$ & & & & & 1 & -0.25 & 0.34 ** \\
\hline ApoA1 (mg/dl) & & & & & & 1 & -0.1 \\
\hline
\end{tabular}

${ }^{\star} P<0.05,{ }^{* \star} P<0.01,{ }^{* \star \star} P<0.001$. 
a women with low baseline serum VEGF

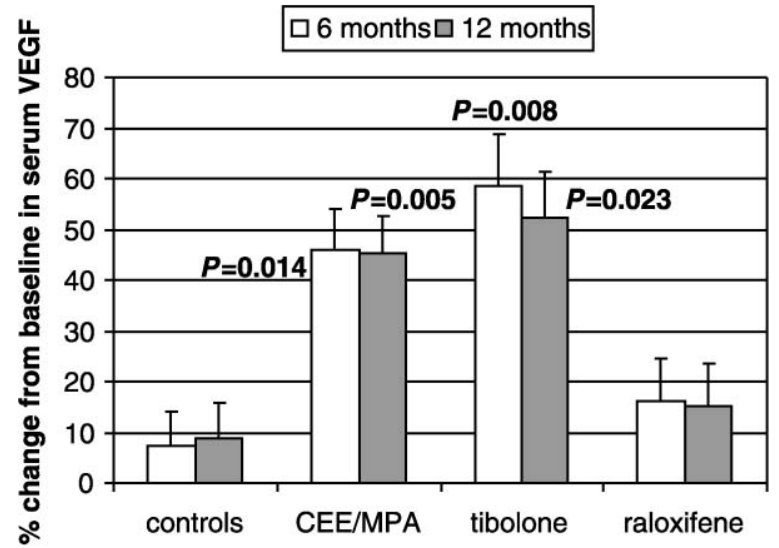

b women with high baseline serum VEGF

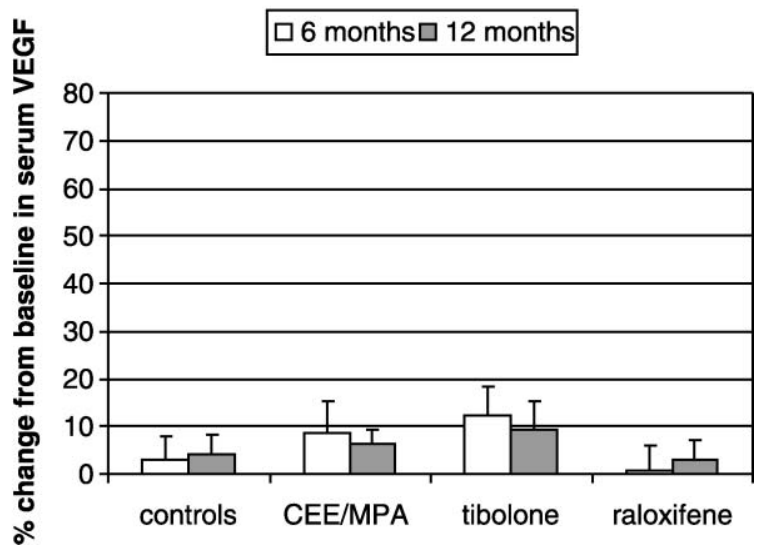

Figure 1 Percentage changes from baseline in plasma VEGF levels at 6 and 12 months under continuous combined HT (CEE/MPA, $2.5 \mathrm{mg}$ tibolone, $60 \mathrm{mg}$ raloxifene or no therapy). (a) Women with low baseline serum VEGF $(<243.2 \mathrm{pg} / \mathrm{ml}$, median for whole sample) and (b) women with high baseline serum VEGF $(>243.2 \mathrm{pg} / \mathrm{ml})$. $P$ values: within group comparisons with baseline values by ANOVA for repeated measures.

treatment on plasma VEGF at 6 and at 12 months was confined to the group of women with low baseline VEGF levels [CEE/MPA baseline: $152.7 \pm 61.7 \mathrm{pg} / \mathrm{ml}$, month 6: $208.8 \pm 105.8 \mathrm{pg} / \mathrm{ml}, \quad P=0.014$, month 12: $208.3 \pm 97.7 \mathrm{pg} / \mathrm{ml}, P=0.005$; tibolone baseline: $110.2 \pm 70.0 \mathrm{pg} / \mathrm{ml}$, month $6: 138.8 \pm 68.1 \mathrm{pg} / \mathrm{ml}, P=$ 0.008 month 12: $139.8 \pm 71.3 \mathrm{pg} / \mathrm{ml}, \quad P=0.023$; Fig. 1a]. On the contrary, CEE/MPA and tibolone had no effect on plasma VEGF in women with high baseline VEGF [CEE/MPA baseline: $374.4 \pm 147.9 \mathrm{pg} / \mathrm{ml}$, month 6: $392.7 \pm 169.5 \mathrm{pg} / \mathrm{ml}, P=0.65$, month 12 : $393.9 \pm 151.6 \mathrm{pg} / \mathrm{ml}, \quad P=0.38$; tibolone baseline: $360.2 \pm 134.0 \mathrm{pg} / \mathrm{ml}$, month $6: 385.4 \pm 154.0 \mathrm{pg} / \mathrm{ml}$, $P=0.59$, month 12: $381.2 \pm 178.9 \mathrm{pg} / \mathrm{ml}, P=0.67$; Fig. 1b]. In both the raloxifene-treated and the control groups, plasma VEGF did not change, in either women with high or women with low baseline VEGF levels.

\section{Discussion}

The results of this study showed that plasma VEGF levels increased significantly in healthy postmenopausal women treated with HT and tibolone as compared with non-treated women. The observed effect of HT and tibolone appeared to be confined to women with lower baseline VEGF levels. On the contrary, raloxifene had no significant effect on plasma VEGF levels.

The results reported to date on the effect of HT on circulating VEGF are equivocal. Sumino et al. (1) have reported that oral HT significantly decreased both VEGF and LDL-C among normocholesterolemic women. On the contrary, Akkad et al. (19) observed a statistically significant increase in serum VEGF levels following continuous transdermal estrogen administration. Furthermore, Zacharieva et al. (20) administering transdermal $17 \beta-E 2$ have reported a significant increase in circulating VEGF. Agrawal et al. (21) reported significantly higher serum VEGF levels in hysterectomized women treated with CEE, transdermal E2 or tibolone and, furthermore, that CEE was associated with higher VEGF levels as compared with transdermal E2 or tibolone.

VEGF and VEGF mRNA are expressed in atherosclerotic arteries and this is further augmented in the presence of lipid disorders and hypertension (1). Increased circulating VEGF has been reported in patients with hyperlipidemia or hypertension who were asymptomatic for atherosclerosis $(22,23)$. In hyperlipidemic patients with or without atherosclerosis, lipid-lowering medication decreases VEGF levels (22). An interactive state between lipoproteins and VEGF has also been suggested (1), as oxidized LDL-C which is abundantly present in the atherosclerotic arterial wall increases VEGF mRNA expression. In our study, baseline ApoB associated positively with baseline VEGF levels. ApoB is a strong predictor for cardiovascular risk, even stronger than LDL-C (24). ApoB, as expected, correlated positively with baseline LDL-C levels, which may indicate a higher presence of oxidized LDL.

Tibolone is a synthetic steroid administered to postmenopausal women for the relief of climacteric symptoms and the prevention of bone loss. Tibolone is an attractive alternative to HT as it is associated with minimal endometrial and breast epithelial stimulation, as well as minimal increase in breast density (25). Similar to Agrawal (21), we have found that tibolone significantly increases serum VEGF levels among healthy postmenopausal women. Tibolone has been reported to decrease HDL-C by as much as 30\% (26). Although it has been suggested that this decrease in HDL-C does not interfere with its ability to prevent LDL oxidation (26), it is possible that tibolone increased VEGF via an increased presence of oxidized LDL. A second possible explanation for the VEGF increase may be the direct effect of the estrogenic action of $3 \alpha$ - and $3 \beta$-hydroxy metabolites of tibolone (27). 
Clinical and experimental studies have indicated that raloxifene expresses an estrogen-agonist action on serum lipids (28) and that it favorably modulates additional factors involved in cardiovascular pathophysiology such as nitric oxide (29), homocysteine (30) and matrix metalloproteinases (31). Dardes et al. (32), evaluating the effect of anti-estrogens on endometrial cancer cells, reported that raloxifene did not increase VEGF secretion. Tamoxifen on the other hand has been reported to induce, similar to $17 \beta-\mathrm{E} 2$, VEGF expression in uterus (33) and in vitro (34) while, in an in vitro EC study, to reduce serum VEGF and inhibit its effect on ECs (35). In an in vitro study (36), raloxifene did not increase mRNA for VEGF isoforms 121 and 165 predominant in the endometrium. To our knowledge, the effect of raloxifene on serum VEGF levels among postmenopausal women has not been investigated. In our study, raloxifene did not exhibit an estrogen-like effect, since it left serum VEGF unchanged.

Evidence suggests that VEGF is involved in the pathophysiology of CVD and that it may express both a beneficial and a harmful effect $(7,10)$. HT has been shown to modulate VEGF levels, so as to safeguard endothelial integrity-function and provide, via physiological angiogenesis, endothelial recovery after injury $(19,37$, 38). Still unknown, however, are the mechanisms involved and also whether the angiogenic properties of VEGF would offer the middle-aged menopausal woman a capillary network which is structurally and functionally normal $(7,37,38)$. In this context, it would be of interest to further clarify the relationship of VEGF to EC expression of matrix-degrading proteases matrix metaloproteinase-2 and -9 , necessary for EC migration and eventual neovascularization $(7,8,13,14,39)$.

In this study, HT and tibolone significantly increased plasma VEGF. In early atheromatosis, the neovascularization associated with VEGF overexpression may, in the young recently menopausal woman, repair the damaged tissue, promote endothelial recovery and attenuate neointimal proliferation $(7,37,40,41)$. On the contrary, neovascularization in advanced atheromatosis may disseminate inflammatory and immunocompetent elements and destabilize the plaque (10, 23). In our study, the significant increase observed under HT and tibolone occurred only in postmenopausal women with low baseline VEGF and ApoB levels. On the contrary, HT and tibolone had no effect on women with high baseline levels of these parameters. These findings may suggest that HT and tibolone have a differential action depending on the cardiovascular risk profile of the postmenopausal women.

The absence of a placebo-treated group poses a limitation in this study. In order to control for confounding factors regarding possible differences between control and treatment groups we repeated statistical analysis after adjustment for T-score in bone densitometry, as osteoporotic individuals may have a different risk profile with respect to CVD (42).
In conclusion, both continuous combined HT and tibolone increased plasma VEGF, while raloxifene had no effect. The above effect appears to be confined to women with low baseline VEGF levels. Further research is needed to clarify the clinical relevance of these findings with respect to cardiovascular risk in postmenopausal women.

\section{References}

1 Sumino H, Nakamura T, Ichikawa S, Tsugiyasu K, Sakamaki T, Sato K, Kobayashi I \& Nagai R. Serum level of vascular endothelial growth factor is decreased by hormone replacement therapy in postmenopausal women without hypercholesterolemia. Atherosclerosis $2000 \mathbf{1 4 8} 189-195$.

2 Ylikorkala O, Lim P \& Caubel P. Effects on serum lipid profiles of continuous combined $17 \beta$-estradiol/norethisterone acetate hormone replacement therapy. Clinical Therapeutics $2000 \mathbf{2 2}$ 622-626.

3 Walsh BW, Paul S, Wild RA, Dean RA, Tracy RP, Cox DA et al. The effects of hormone replacement therapy and raloxifene on C-reactive protein and homocysteine in healthy postmenopausal women: a randomized controlled trial. Journal of Clinical Endocrinology and Metabolism 200085 214-218.

4 Cicinelli E, Matteo G, Ignarro LJ et al. Acute effects of transdermal estradiol administration on serum levels of nitric oxide in postmenopausal women. Fertility and Sterility 1997 67 63-66.

5 The Writing Group for the Women's Health Initiative Investigators, Risks and benefits of estrogen plus progestin in healthy postmenopausal women. Journal of the American Medical Association $2002 \mathbf{2 8 8} 321-333$.

6 Hulley S, Grady D, Bush T, Furberg C, Herrington D, Riggs B et al. Randomized trial of estrogen plus progestin for secondary prevention of coronary heart disease in postmenopausal women: Heart and Estrogen/Progestin Replacement Study (HERS) Research Group. Journal of the American Medical Association $1998 \mathbf{2 8 0}$ 605-613.

7 Epstein SE, Kornowski R, Fuchs S \& Dvorak HF. Angiogenesis therapy: amidst the hype, the neglected potential for serious side effects. Circulation $2001 \mathbf{1 0 4} 115-119$.

8 Geva E \& Jaffe RB. Role of vascular endothelial growth factor in ovarian physiology and pathology. Fertility and Sterility 2000 74 429-438.

9 Agrawal R, Conway GS, Sladkevicius P, Payne NN, Bekir J, Campbell $\mathrm{S}$ et al. Serum vascular endothelial growth factor (VEGF) in the normal menstrual cycle: association with changes in ovarian and uterine Doppler blood flow. Clinical Endocrinology $199950101-106$.

10 Waltenberger J. Modulation of growth factor action. Implication for the treatment of cardiovascular diseases. Circulation 1997 96 4083-4094.

11 Friedman CI, Danforth DR, Herbosa-Encarnacion C, Arbogast L, Alak BM \& Seifer DB. Follicular fluid vascular endothelial growth factor concentrations are elevated in women of advanced reproductive age undergoing ovulation induction. Fertility and Sterility $1997 \mathbf{6 8} 607-612$.

12 Agrawal R, Prelevic G, Conway GS, Payne NN, Ginsburg J \& Jacobs HS. Serum vascular endothelial growth factor concentrations in postmenopausal women: the effect of hormone replacement therapy. Fertility and Sterility 200073 56-60.

13 Timar J, Döme B, Fazekas K, Janovics A \& Paku S. Angiogenesisdependent diseases and angiogenesis therapy. Pathology Oncology Research $2001785-94$.

14 Kobayashi M, Matsubara J, Matsushita M, Mishikimi N, Sakurai T \& Nimura Y. Expression of angiogenesis and angiogenic factors in human aortic vascular disease. Journal of Surgical Research 2002 $106239-245$.

15 Zhao Q, Egashira K, Inoue S, Usui M, Kitamoto S, Ni W et al. Vascular endothelial growth factor is necessary in the development of 
arteriosclerosis by recruiting/activating monocytes in a rat model of long-term inhibition of nitric oxide synthesis. Circulation 2002 $1051110-1115$.

16 Freedman SB \& Isner JM. Therapeutic angiogenesis for coronary artery disease. Annals of Internal Medicine 2002136 54-71.

17 Celletti FL, Waugh JM, Amabile PG, Brendolan A, Hilfiker PR \& Dake MD. Vascular endothelial growth factor enhances atherosclerotic plaque progression. Nature Medicine 20017 425-429.

18 Rifai N, Warnick GC, McNamara JR, Belcher JD, Grinstead GF \& Frantz ID, Jr. Measurement of low-density lipoprotein cholesterol in serum: a status report. Clinical Chemistry 199238 150-160.

19 Akkad A \& Al-Azzawi F. Changes in serum vascular endothelial growth factor following initiation of estrogen replacement after hysterectomy and oophorectomy. Acta Obstetrica et Gynecologica Scandinavica $200180554-558$.

20 Zacharieva S, Atanassova I, Kirilov G, Kalinov K, Shigarminova R, Nachev E et al. Effect of transdermal estrogen therapy on some vasoactive humoral factors and 24-h ambulatory blood pressure in normotensive postmenopausal women. Climacteric $2002 \mathbf{5}$ 293-299.

21 Agrawal R, Prelevic G, Conway GS, Payne NN, Ginsburg J \& Jacobs HS. Serum vascular endothelial growth factor concentrations in postmenopausal women: the effect of hormone replacement therapy. Fertility and Sterility 200073 56-60.

22 Belgore FM, Lip GYH \& Blann AD. Successful therapy reduces levels of vascular endothelial growth factor (VEGF) in patients with hypertension and patients with hypercholesterolemia. Atherosclerosis $2000 \mathbf{1 5 1} 599$.

23 Blann AD, Belgore FM, Constans J, Conri C \& Lip GY. Plasma vascular endothelial growth factor and its receptor Flt-1 in patients with hyperlipidemia and atherosclerosis and the effects of fluvastatin or fenofibrate. American Journal of Cardiology $2001 \mathbf{8 7}$ $1160-1163$

24 Walldius G \& Junger I. Apolipoprotein B and apolipoprotein A-1: risk indicators of coronary heart disease and targets for lipid-modifying therapy. Journal of Internal Medicine 2004255 188-205.

25 Modelska K \& Cummings S. Tibolone for postmenopausal women: systematic review of randomized trials. Journal of Clinical Endocrinology and Metabolism 200287 16-23.

26 von Eckardstein A, Schmiddem K, Hovels A, Gulbahce E, SchulerLuttmann S, Elbers J, Helmond F, Bennink HJ \& Assmann G. Lowering of HDL cholesterol in postmenopausal women is not associated with changes in cholesterol efflux capacity or paraoxonase activity. Atherosclerosis $2001159433-439$.

27 De Gooyer M, Deckers G, Schoonen W, Verheul H \& Kloosterboer H. Receptor profiling and endocrine interactions of tibolone. Steroids $20036821-30$.

28 Walsh BW, Kuller LH, Wild RA, Paul S, Farmer M, Lawrence JB et al. Effects of raloxifene on serum lipids and coagulation factors in healthy postmenopausal women. Journal of the American Medical Association 1998279 1445-1451.

29 Christodoulakos G, Panoulis C, Kouskouni E, Chondros C, Dendrinos S \& Creatsas G. Effects of estrogen-progestin and raloxifene therapy on nitric oxide, prostacyclin and endothelin-1 synthesis. Gynecology and Endocrinology 200216 9-17.

30 Walsh BW, Paul S, Wild RA, Dean RA, Tracy RP, Cox DA et al. The effects of hormone replacement therapy and raloxifene on
C-reactive protein and homocysteine in healthy postmenopausal women: a randomized controlled trial. Journal of Clinical Endocrinology and Metabolism $2000 \mathbf{8 5} 214-218$.

31 Christodoulakos G, Panoulis C, Lambrinoudaki I, Botsis D, Dendrinos S, Economou E et al. The effect of hormone replacement therapy and raloxifene on serum matrix metalloproteinases -2 and -9 in postmenopausal women. Menopause $200411299-305$.

32 Dardes RC, Schafer JM, Pearce ST, Osipo C, Chen B \& Jordan VC. Regulation of estrogen target genes and growth by selective estrogen-receptor modulators in endometrial cancer cells. Gynecology and Oncology $200285498-506$.

33 Bausero P, Ben-Mahdi M, Mazucatelli J, Bloy C \& Perrot-Applanat M. Vascular endothelial growth factor is modulated in vascular muscle cells by estradiol, tamoxifen, and hypoxia. American Journal of Physiology. Heart and Circulatory Physiology 2000279 H2033-H2042.

34 Hyder SM, Chiappetta C, Murthy L \& Stancel GM. Selective inhibition of estrogen-regulated gene expression in vivo by the pure antiestrogen ICI 182,780. Cancer Research $1997572547-2549$.

35 McNamara DA, Harmey J, Wang JH, Kay E, Walsh TN \& BouchierHayes DJ. Tamoxifen inhibits endothelial cell proliferation and attenuates VEGF-mediated angiogenesis and migration in vivo. European Journal of Surgery and Oncology 2001 27 714-718.

36 Navarro FJ, Mirkin S \& Archer DF. Effect of raloxifene, 17betaestradiol, and progesterone on mRNA for vascular endothelial growth factor isoforms 121 and 165 and thrombospondin-1 in Ishikawa cells. Fertility and Sterility 200379 1409-1415.

37 Krasinski K, Spyridopoulos I, Asahara T, van der Zee R, Isner JM \& Losordo DW. Estradiol accelerates functional endothelial recovery after arterial injury. Circulation 199795 1768-1772.

38 Jesmin S, Sakuma I, Hattori Y \& Kitabatake A. In vivo estrogen manipulations on coronary capillary network and angiogenic molecule expression in middle-aged female rats. Arteriosclerosis, Thrombosis and Vascular Biology 200222 1591-1597.

39 Zanger D, Yang BK, Ardans J, Waclawiw MA, Csako G, Wahl LM et al. Divergent effects of hormone therapy on serum markers of inflammation in postmenopausal women with coronary artery disease on appropriate medical management. Journal of the American College of Cardiologists 200036 1797-1802.

40 Couffinhal T, Kearney M, Witzenbichler B, Chen D, Murohara T \& Losordo DW. Vascular endothelial growth factor/vascular permeability factor (VEGF/VPF) in normal and atherosclerotic human arteries. American Journal of Pathology $1997 \mathbf{1 5 0}$ $1673-1685$.

41 Cotton JM, Mathur A, Hong Y, Brown AS, Martin JF \& Erusalimsky JD. Acute rise of circulating vascular endothelial growth factor-A in patients with coronary heart disease following cardiothoracic surgery. European Heart Journal 200223 953-959.

42 McFarlane SI, Myniyappa R, Shin JJ, Bahtiyar G \& Sowers JR. Osteoporosis and cardiovascular disease: brittle bones and bones arteries, is there a link? Endocrine $2004231-10$.

Received 23 April 2004

Accepted 3 May 2004 